\title{
Subgrupo de investigação em Educação, Tecnologia e Sociedade
}

\author{
Fernando Albuquerque Costa, Carla Rodriguez, Elisabete Cruz, Helena Peralta, \\ Joana Viana, Sandra Fradão, Eloisa Branco, Nádia Gomes, Cátia Santos
}

\author{
Instituto de Educação - Universidade de Lisboa (IEUL) \\ Alameda da Universidade - 1649-013 - Lisboa - Portugal \\ \{fc, crpaiva, ecruz, hperalta, jviana, sjeradao\} eie.ul.pt, \\ \{eloisabranco,nsfgomes\}@gmail.com, katy_cls@hotmail.com
}

O subgrupo aqui apresentado é parte do grupo Educação Tecnologia e Sociedade (ETS), do Instituto de Educação da Universidade de Lisboa (IEUL), e tem como principal objetivo desenvolver projetos de investigação no âmbito do uso das Tecnologias de Informação e Comunicação (TIC) na educação.

Entre outras, constituem-se como linhas prioritárias de investigação: a promoção da aprendizagem com TIC em contextos educativos e formativos; o desenvolvimento profissional e as competências dos professores em TIC; o desenvolvimento de recursos educativos digitais; a cultura digital e as competências para o Século XXI e o impacto de políticas públicas no domínio das TIC na educação. Dentro destas linhas de investigação, o subgrupo em questão apoia a oferta formativa ao nível da pósgraduação, acolhendo, no âmbito de seus projetos de investigação, alunos de mestrado, doutoramento e pós-doutoramento. O subgrupo é responsável ainda por estudos e atividades de assessoria a entidades públicas e privadas no domínio da utilização e integração das TIC em espaços educativos.

Atualmente estão em curso dois projetos: 1. Escol@ Digit@1 (apoiado pelo IEUL e pela Editora Santillana (2012-2015)), que visa promover a cultura digital na escola, envolvendo para isso toda a comunidade escolar em ações de formação e integração curricular das tecnologias e 2. TACCLE2 - "Teachers' Aids on Creating Content for Learning Environments" (ação multilateral IEUL-COMENIUS (2011-2014)), projeto que envolve universidades e outras instituições de diferentes países europeus na elaboração de materiais e estratégias para a formação de professores, que possam vir a estimular a utilização inovadora das TIC em contextos educativos.

Alguns dos projetos já desenvolvidos pelo subgrupo na área: 1. Programa de Operacionalização de Metas de Aprendizagem em TIC para o Ensino Básico e Secundário (Ministério da Educação (2010-2012)); 2. Estudo de implementação do sistema de formação e certificação de competências em TIC (Plano Tecnológico da Educação, Gabinete de Estatística e Planeamento da Educação do Ministério da Educação (2008)). 3. IPETCCO - "Supporting Innovation", projeto que envolveu universidades de diferentes países europeus, na área da formação de professores, para a utilização pedagógica das TIC. (Comissão Europeia, Programa SOCRATES, Ação MINERVA (2001-2004)). 4. PEDACTICE - "Educational Multimedia in Compulsory School: From Pedagogical Assessment to Product Assessment" (1997-2000), projeto de âmbito europeu, financiado pela Multimedia Task Force, da União Europeia, sobre a utilização e avaliação de software multimédia educativo. 